\title{
POWER AND COMBUSTION
}

$\mathrm{P}$ ROF. A. C. G. EGERTON delivered the twentyseventh Thomas Hawksley Lecture of the Institution of Mechanical Engineers on November 15 last. At the outset, he emphasized the fact that the sun is the source of practically all power on earth. Its surface (photosphere) has a brightness temperature of $6,000^{\circ} \mathrm{C}$., and radiates energy at the rate of $3.8 \times 10^{33}$ ergs per second. This radiant should it become available as a result of the artificial fission of uranium, it will also represent part of the energy derived from the sun, since the earth was born of the sun. Energy might also in theory be derived from any region where differences of temperature are maintained by natural means ; for example, the lower and upper layers of tropical seas. The energy of lightning might be harnessed, but its

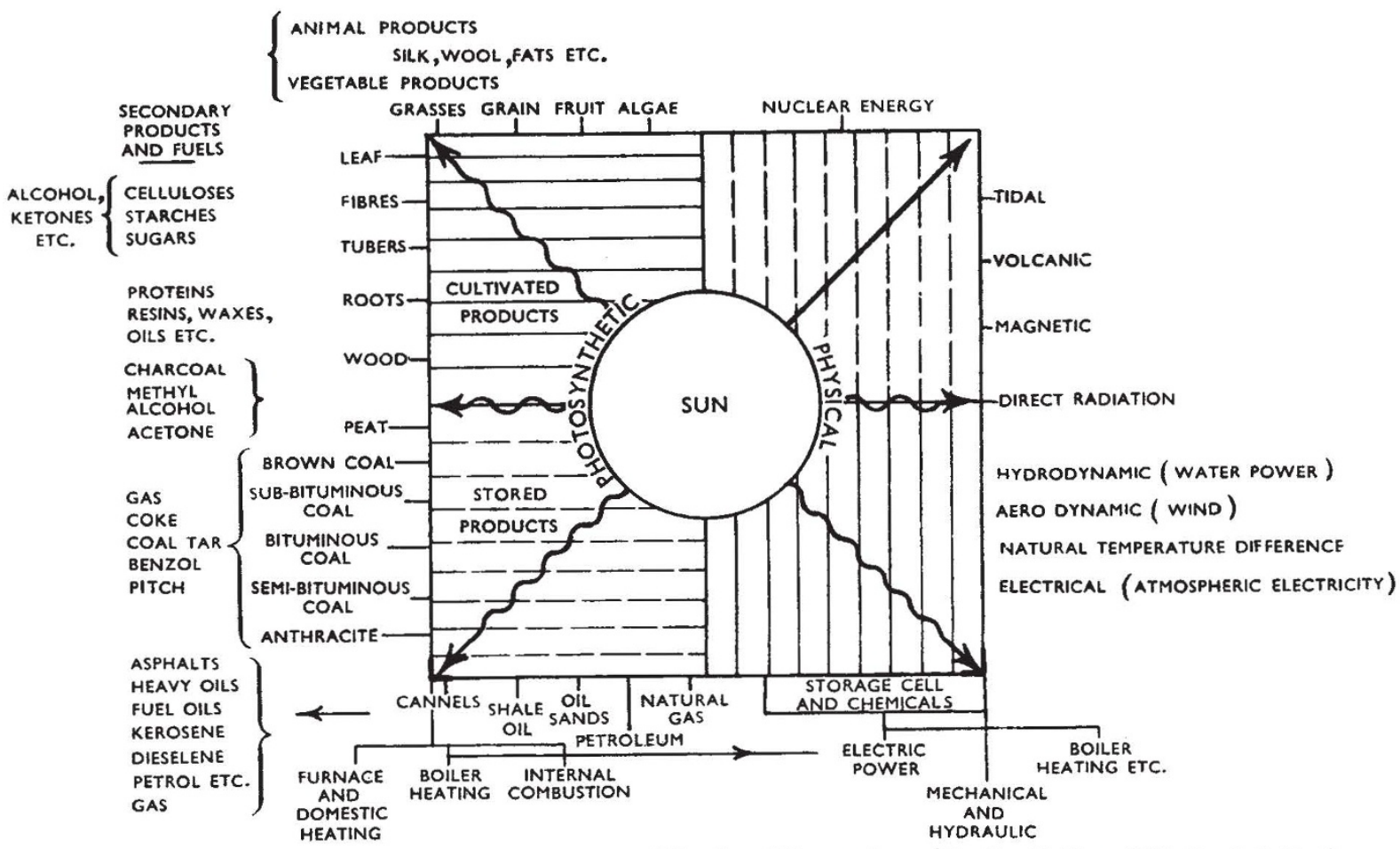

Fig. 1. [By courtesy of the Institution of Mechanical Engineers

energy works a great engine of $2 \cdot 3 \times 10^{14}$ h.p. wherein the sun is the furnace, the atmosphere is both working substance and cylinder, and space the condenser. Within the workings of this engine potential energy is being converted to kinetic ; kinetic back into potential. Approximately 35 per cent of the energy of radiation is used in evaporating waters of the ocean and the land. On condensation the energy is released: some returns as kinetic energy of the rain or the rivers; some appears in the wind and thunderstorms.

Tidal power, which is mainly derived from the gravitational effect of the mass of the moon, also falls within the whole scheme of solar energy, for the moon was born of the earth. Volcanic power represents the energy remaining of that with which the earth was originally endowed by the sun and is maintained by the sun's radiant energy, which prevents further cooling. Atomic energy, or the conversion of the matter of the earth into energy, is now an enormous source of potential power, and total contribution throughout the world would be small.

At this point in his lecture Prof. Egerton examined the nature of power and pointed out that there are two kinds: the power that drives, and the power that directs. Human beings are able to direct the activities of Nature and thus obtain power from the effects of the sun on the atmosphere. There is, however, another factor which is capable of directing power, and that is plant life. Photosynthesis takes place within the cells of the plant as the result of the utilization of radiant energy falling on its surfaces. The products of photosynthesis are valuable sources of power. The origin of coal is certainly vegetable, and the origin of oil is, according to the author, almost certainly mainly vegetable.

Fig. 1 serves to summarize the various sources of power discussed by Prof. Egerton. The section shaded with broken vertical lines indicates physical sources dependent on solar radiation and utilized mainly by means of hydro-electric stations. The section shaded 
with full horizontal lines refers to the products of photosynthesis. The section shaded with broken horizontal lines indicates those products which have gradually been stored throughout geological time.

The two main sources of power are hydro-electric power and power from stored fuel. The latter has the advantage that the energy can be transported where it is needed.

After an admitted digression which included dis- mechanism of the body in action, food energy is 'down-graded'. Waste in either the 'up-grading' or 'down-grading' process should not be tolerated if the best use is to be made of radiant energy. Other essentials of life besides food and water include clothing, shelter, warmth and rest. Some of these are obtained through fuels, others through treatment of agricultural products. Sometimes the agricultural product is broken down; sometimes it is preferable to build up from the fuel.

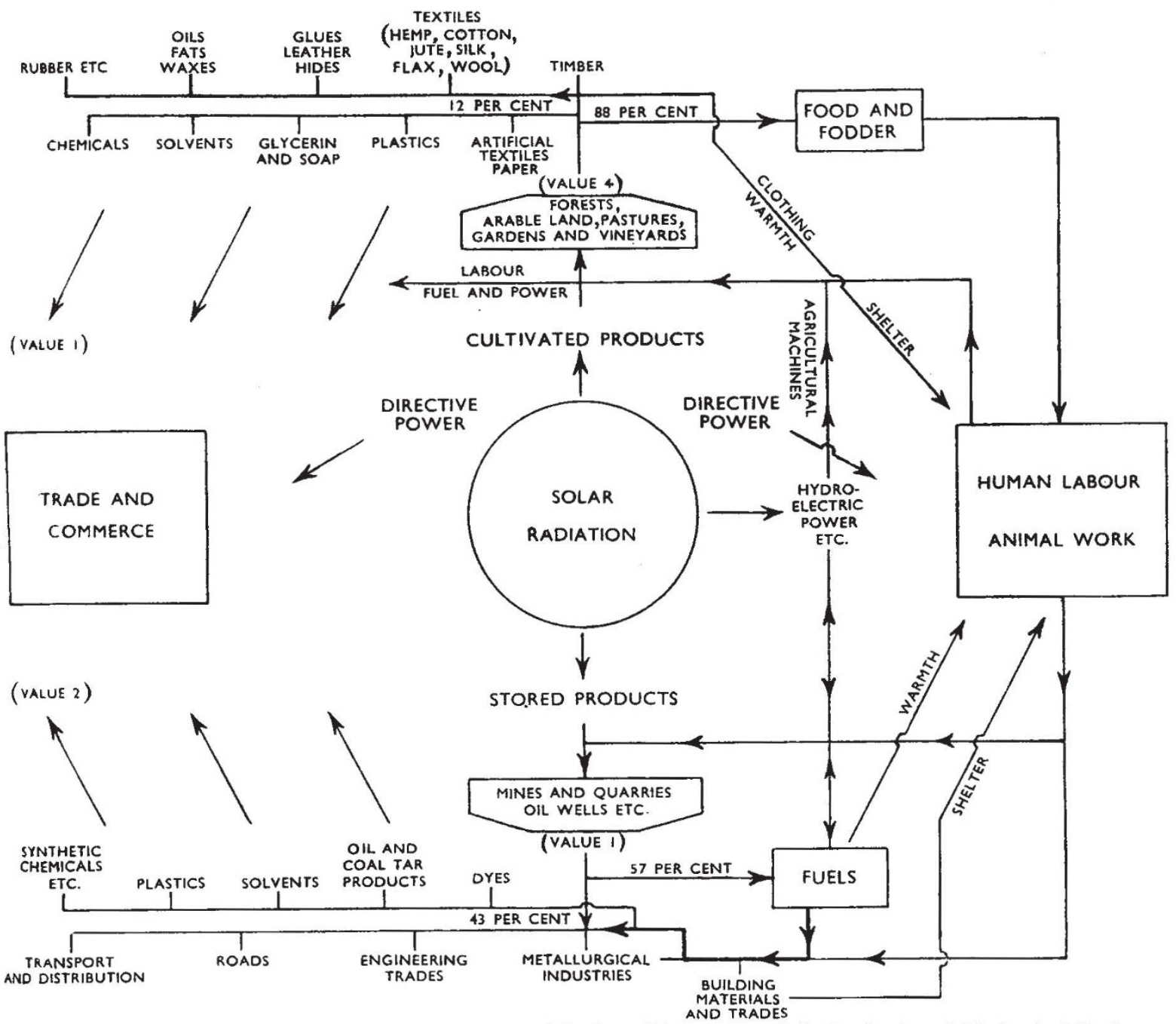

Fig 2. [By courtesy of the Institution of Mechanical Engineers

cussion of some interesting problems of combustion, ignition of hydrocarbons, 'knock' and treatment of petroleum, Prof. Egerton returned to the main theme of his lecture and summarized conclusions reached by means of a diagram of human activities (Fig. 2). Starting from the centre, solar radiation provides stored and cultivated products. The energy value of the foods produced would be less than a tenth of the fuel produced, but the gold value of the foodstuffs is far greater than the value of all other production. Food provides energy for the worker, and fuels supplement his work. In this way the energy is as it were 'up-graded' in order that exchange may be made for food. In the process of keeping the
In conclusion, Prof. Egerton suggested that some control should be exercised over primary fuels and over wheat, which is the key food. In this way the riches of the earth would not be squandered and the material economy of the earth might be run far more smoothly. He also suggested that as much power as possible should be derived from the solar energy which is continuously being showered upon the earth $(60,000$ times as much as the energy at present being used) rather than from inherited stores. In other words, a greater distinction should be drawn be. tween the use of real irreplaceable capital and replaceable products which the sun provides on the earth. 